\title{
Priority based Energy Distribution for Off-grid Rural Electrification
}

\author{
Siva Raja Sindiramutty ${ }^{1}$, Chong Eng Tan ${ }^{2}$, Sei Ping Lau ${ }^{3}$ \\ Faculty of Computer Science and Information Technology \\ University Malaysia Sarawak, Kota Samarahan, Sarawak
}

\begin{abstract}
Rural off-grid electrification is always very challenging due to mostly using limited output renewable energy source such as solar power system. Owing to its nature of power generation that depends on weather condition, the reliability in power provision is often affected by uncontrolled overwhelming usage or bad weather condition. Total power system blackout that frequently happens not only disturb the night activity routine but also can be life threatening if the rural community is unable to initiate telephony communication with the outside world during state of emergency due to power outage. In order to reduce the frequency of total system blackout caused by the reasons mentioned, we proposed a priority-based energy distribution scheme to assist the off-grid standalone solar power system to improve the overall operating hours of the critical appliances in rural areas. The scheme takes into consideration of criticality of the home appliances as defined by the rural users, so that the system would distribute power supply based on the current state of the system with an objective to prolong the service availability of the critical appliances that matter the most to the users. The scheme has been evaluated under simulated scenario and has shown a $100 \%$ operation availability of the critical appliance is achievable even during bad weather season that has very low solar input.
\end{abstract}

Keywords-PI (Panel Input); BP (Battery Power); critical appliances; non-critical appliances; prioritization; operating hour

\section{INTRODUCTION}

In this modern world, electrical power supply has become so commonly available and it has been a necessity in daily living. Most people living in the urban never have to worry about power provision as there are plenty and cheap. While more energy has been provision to support more applications, the increasing release of greenhouse gases that cause global warming has risen the attention to adopt greener renewable energy sources that have minimal deleterious on nature $[1,2]$. On the other hand, while the urban is thinking hard on how to embrace greener renewable energy sources, the rural areas have long been depending on renewable energy power source. The adoption of renewable energy sources such as solar power in rural areas because they are usually not part of the nationwide power grid network hence standalone renewable energy sources are the better option compared to using the highly polluted diesel power generator. The standalone solar power systems have limited power capacity and not very reliable. Many factors such as weather conditions, unpredictable usage load and battery cells deterioration can easily interrupt power availability. In the case of Malaysia especially in the states of Sarawak and Sabah, many of the rural living still rely heavily on standalone power generators powered by diesel fuel but slowly migrating towards renewable energy sources. Rural electrification programs have been initiated by the government to provision off-grid power supply to small villages but owing to rural populations are very scattered and in large quantity, many villages are still waiting for the electrification program to reach them. The wait could be another 5 to 10 years subject to the planning and priority to implement. The standalone off-grid power systems are usually powered through solar diesel hybrid system due to Malaysia located in a region with plenty of sunlight throughout the year and the diesel generators are used as backup during rainy seasons. Renewable energy source such as solar power is an excellent renewable energy source but since it can be easily affected by bad weather or overwhelming usage, there is a need to look into how to strike a balance between the power generated and its usage. Our research works have been investigating the possibility to make optimum use of the amount of power generated in order to improve the overall sustainability of power supply in a more intelligent way. Upgrading and up-scaling the solar power system may solve the power supply issues in short term with an expense of higher cost, but that is not the direction we are looking at. Our approach is to maintain the same solar power system and introduce a new power distribution scheme to prevent total power blackout which happened every time the system running out of power. Our proposed priority-based energy distribution scheme shall ensure critical appliances and emergency communication equipment will still operational at all time without being affected by overwhelming power usage by other non-critical appliances.

This paper has been structured into five sections. Section II explains the background information that leads to the problem that this research is trying to solve. The nature of the solar power system and its importance role in serving the rural areas are also being described. Section III highlights the existing works on power management and schemes by other researchers. Unfortunately, none of the existing works taking rural daily living needs as the main consideration for solution formulation. Section IV describes the design philosophy of the proposed priority-based energy distribution scheme and how it works in ensuring the continuous operation of the critical appliances. Section V presents the simulation results that compare the proposed scheme to standard solar system under different power input and load scenario. The comparison has shown that under simulated environment, total power blackout can be prevented with the adoption of the new scheme. 
Section VI concludes the paper by highlighting the impact of the new scheme to rural living.

\section{BACKGROUND}

Since solar power is a more convincing energy source in Malaysia owing to its location is closer to the equator and having high yearly irradiance throughout the year, the solar power system has been chosen as the target platform to be enhanced via the new energy prioritize scheme. The greatest advantage of solar power system is that it is renewable daily with sunrise, and it can be implemented almost anywhere within Malaysia [3]. Fig. 1 shows the yearly average irradiance of various locations in Malaysia which indicates relatively high irradiance values that are promising for solar power system implementation.

Solar power system or photovoltaic (PV) system is one of the favorable renewable energy sources in Malaysia. Despite the energy generation efficiency of the system relatively lower than other renewable energy systems, it has the convenience that it is almost pollution free, with relatively small in sustainment and the operating cost is almost free $[4,5]$. Each solar cell in a solar panel module generates only about onehalf of the electricity and scads of individual solar cells are linked in a sealed, weather proof packages knows as Photovoltaic module [6]. The photovoltaic modules can be connected either in parallel, series or both which known as the Photovoltaic array. This array will eventually connect to power supply module and then to the appliances or to the power grid network. However, solar power systems have some drawbacks in conversion efficiency and the power produced is very much depending on weather condition, scattering of direct sunlight by the atmosphere, tilt angle of the PV solar panels and declination [7, 8]. A standalone off-grid implementation of solar power system for home is illustrated in Fig. 2.

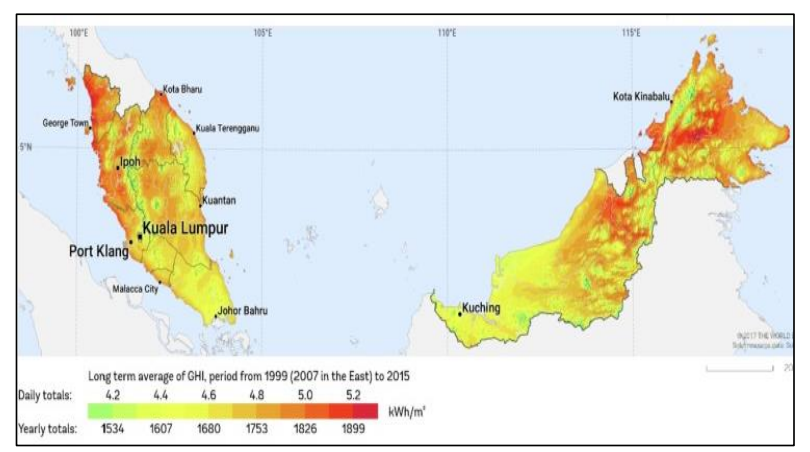

Fig 1. Solar Radiation in Malaysia [3].

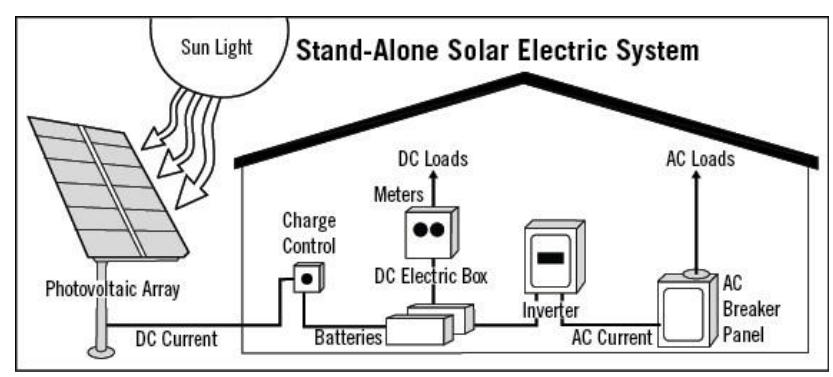

Fig 2. Standalone Solar Power System [9].
The characteristics of such solar power system design have several disadvantages in its application. The power supply is coming from a single source which is from the solar panel to the battery sub-system, where all appliances have equal access to all power available in the system. This is usually the weakest link in the system design that could easily bring down the power system and cause total power blackout. Excessive usage of power by any appliance cannot be controlled by the system and it may use up all reserved power in the battery sub-system at any time. Owing to that, solar power system design will have to take into account the expected loads of the system. An additional of $25 \%$ to $30 \%$ of excess capacity will also be added to the design to compensate future usage growth. Even so, any sudden increase in usage that exceed the maximum capacity of the system will still trigger power blackout.

This is a commonly problem for power system with a fixed capacity, any unexpected overwhelming usage will just bring down the entire power supply system. This is also the reason many solar system users have the perception that the reliability of solar power system is usually below par. It is not easy to educate users to learn how to self-control in daily power usage, furthermore the manual calculation of conserving power is still too complicated for users with little knowledge in electrical system. Hence, based on the current problem, in order to achieve a better usage experience on a standalone solar power system for home or village, some intelligence can be useful in controlling and regulating the power usage. An intelligently regulated power supply system would be able to prevent frequent system blackout that causes service interruption to all other appliances. Among home appliances, a good power distribution control design shall ensure if not all appliances but some of the more critical appliances such as the basic lighting and emergency communication device to continue to operate even in an event of power shortage.

On top of that, even though solar irradiance is generally high within the region of Malaysia, there are relatively large differences in the amount of yearly irradiance at different locations across the country. The differences in the yearly irradiance would affect the scale and capacity of the solar power system to be implemented. A standardized solar power system design or model may not serve well in all locations with difference yearly irradiance. The frequency of system blackout may be higher in locations with relatively lower irradiance and solar system scale may be over provision in locations with relatively higher irradiance. As shown in Fig. 1 above, the lowest and the highest irradiance differences at different locations can be up to $30 \%$. Also, the solar system reserve capacity design is usually based on the average irradiance which may not accurately capture the actual on-theday situation. In Table I, we can see the seven days reading of energy collected (watt-hour) at three different locations in Malaysia. The daily differences in daily energy collected can be up to $71 \%$ below the weekly average in Kuala Lumpur, $33.5 \%$ in Pulau Pinang and 30.8\% in Kelantan. With such a significance variation in energy collection between days in the same location, it certainly imposes a great challenge to any standardized solar power system design to cope without experiencing blackout on the specific day of extremely low solar output [10]. 
TABLE I. SOLAR OUTPUT FOR ONE WEEK IN 3 SELECTED LOCATIONS IN MALAYSIA

\begin{tabular}{|l|l|l|l|}
\hline \multicolumn{4}{|l|}{ Energy (Wh/Day) } \\
\hline Day & Kuala Lumpur & Pulau Pinang & Kelantan \\
\hline 1 & 1145.30 & 2483.72 & 3572.67 \\
\hline 2 & 1396.09 & 2589.24 & 2809.43 \\
\hline 3 & 2802.60 & 2404.76 & 4325.82 \\
\hline 4 & 523.53 & 3180.18 & 5907.11 \\
\hline 5 & 1473.49 & 4326.03 & 2498.41 \\
\hline 6 & 4115.35 & 5929.76 & 3084.14 \\
\hline 7 & 1177.30 & 4410.37 & 3081.38 \\
\hline
\end{tabular}

\section{RELATED WORK}

Throughout the years, intelligent energy management has been the focus of research to maximize and optimize the use of energy for various applications. Saher et al. [11] proposed a priority based maximum consuming power control for smart homes. The proposed system composed of modules such as smart electric sensors (SESs), power provisioning controller (PPC) and home appliances (HA). The PPC functions are to collect ON/OFF information from the connected HA and the immediate power consumption level from the SES, and to send control signal to each HA. After the PPC obtains the data, along with HA priority, it calculates the final target power level of each HA. Those modules are very essential parts of the system, because they control the maximum total power consumption in comprehensive transient behavior considering heterogeneous HAs with different time given. On the other hand, Miroslav \& Ales [12] presented design and implementation of a priority based smart home simulation (SHS) system. The proposed system is constructed using the multi-agent approach, where the overall consumption control comes mostly through the inter-agent communication. The presented communication model has been implemented using low performance controllers with limited computational power. Manisa et al. [13] proposed an algorithm for intelligent home energy management (HEM) and to perform demand response analysis for managing high power consumption household appliances. The proposed algorithm handles the home appliances according to their priority and makes sure the total power consumptions are below predefined level. Xin et al. [14] presented a real time household load priority scheduling algorithm based on prediction of renewable source availability. The proposed system is to increase the advantages of renewable energy and reduce the total cost of energy consumption with home users comfort constraints. HA have been allocated dynamic priority based on their different energy consumptions modes and their current status. In every hour, weather condition is taken into account to predict the availability of renewable energy sources. According to the assigned priority, HAs are scheduled based on the predicted output of renewable energy and the forecast electricity. Takekazu et al. [15] comes with a concept of i-Energy as the new energy management algorithm to be aware of efficient and versatile control of e-power flows together with decentralized energy generation and home appliances and offices. The i-Energy idea is best characterized by a new energy management method called Energy on Demand (EoD). Benefits of EoD can achieve the guaranteed minimal energy consumption without jeopardize the quality of living. EoD introduces a new concept which is the explicit demand-based power supply control, a best-effort power distribution method based on appliances priorities and setting ceiling control for power consumption.

Gill et al. [16] invented a ZigBee based home automation system that integrates via the basic home WiFi gateway. The proposed system permits home users to observe and manage the connected appliances in the home, via a plenty of control, including a ZigBee based remote control, and support for WiFi enabled hardware which supports Java. Home users are able to observe and control remotely their home appliances using Internet enable device with Java support. A home gateway is deployed to ease interoperability between heterogeneous networks and gives a consistent interface, regardless of the accessing appliances. Han et al. [17], [18] presented new HEM concept adaptation from ZigBee. Their proposed system in [17] introduces a smart home interfaces and device definitions to permits interoperability together with ZigBee appliances manufactured by different manufactures of electrical appliances, meters and smart energy enabling products. Whereas in [18], a new routing protocol Disjoints Multi Path based Routing (DMPR) is proposed to increase the performance of the ZigBee sensor network. The idea innovates the proposed home energy control systems design that gives intelligent services to home users. Zhao et al. [19] proposed an energy management system for building structures using a multi agent decision making control methodology for building energy management systems (BEMS) for electrical, heating, and cooling energy zones with combined heat and power system optimizations focus at increasing energy efficiency and minimizing the energy cost. Nhat-Hai et al. [20] also initiated the idea for BEMS.

The proposed system is a real time control using wireless sensor network for intelligent BEMS in buildings. Whereas Hiroshi et al. [21] proposed adaptive HEMs/BEMS for controlling energy consumption using the convergence of heterogeneous. Yuvraj et al. [22] presented an occupancy driven energy management for smart building automation that can be used for accurate occupancy detection at the level of individual offices. Using the proposed system, one can achieve potential energy saving of $10 \%$ to $15 \%$. Wei et al. [23] proposed a design of energy consumption monitoring and energy saving management system of intelligent building based on the internet of things which has some improvement in the building energy and control, and increases the energy saving of intelligent building. This system is based on wireless network sensors network using the internet of things technology, a detailed analysis of building energy consumption on intelligent building automation systems and appliance, optimum use of good advantages of sensor networks gathers environment data on energy consumption.

Among all works done on intelligence control of power system, none of the design context is focusing on the prioritization of applications for the implementation for rural living and environment. The unique needs of rural living such as basic lighting, difficult in physical access and dependency 
on remote communication service shall be given a priority access to the very limited resource off-grid power system in order to sustain the service even when the system is under very low energy input.

\section{THE PRIORITY-BASED ENERGY DISTRUBUTION SCHEME FOR RURAL APPLICATION}

\section{A. The Concept}

The proposed priority-based energy distribution scheme for rural home appliances have been designed based on the rural living context where several environment factors have been taken into consideration in the overall scheme design. The concept of prioritization is to ensure appliances that are being labeled as critical will continue to operate and survive the total power blackout caused by unpredictable overwhelming usage and also low renewable energy input during rainy seasons. The scheme will be focusing on renewable energy sources, in this case the solar power system, designed for home. Owing to solar power systems are designed based on pre-calculated load profile and usage assumptions, there will be time where the system has to operate outside of these assumptions and calculations. When such time comes, system power blackout is unavoidable as the system design does not give early warning and even if warning is given, how should the users react to it and who should be stopping the use of power in order to prevent unwanted total system blackout. This can be a very complicated situation to deal with among the users on a centralized standalone solar power system. Hence, we proposed a priority-based energy distribution scheme that would decide in advance which appliances will have to go offline earlier than another so that even under the most power constraint situation, the users will still have access to the most critical appliances pre-defined earlier. Under this scheme, the power supply to each home appliance will be categorized into several groups such as critical, semi-critical and standard, or even allocate individual power port for different appliances so that prioritization control can go down to each individual appliance.

Given the required conditions to the central controller of the prioritization controller module, the solar panel input (PI) and the battery capacity (BP) are being monitor closely. The monitored parameters, $\mathrm{PI}$ and $\mathrm{BP}$ indicate the energy sustainability of the system to support all the connected appliances. Various parameter thresholds are being setup for sustaining different combination of appliances, for example, during the period where the solar is operating under standard designed condition, power will be distributed to all appliances equally, but when the solar input over a period of time is getting critically low, some of the less critical appliances will be cut off from the power supply as a counter measure to conserve energy for other more critical appliances. Under the situation where the battery power is in critically low state, only the most critical appliance is allowed to operate and the rest of the appliances will have to give way to ensure the survival of these devices. In our case here, we define that the telephony is the most critical appliance that should always be kept active for any unforeseen event of emergency. The rural areas have very challenging road assess and lack of communication mean, hence if there is one that is active, it should be kept alive undisturbed. The semi-critical appliance will be the basic lighting for home, which include a very limited number of low power light bulbs to continue lit the house for night activities. The criticality of an appliance is subject to the need of the rural community and their priority can be changed from time to time as deem required.

The priority-based energy distribution scheme will regulate the power so that it will make sure that all the critical appliances will continue to operate by its allocated amount of power. The proposed scheme will have intelligence to separate the critical and non-critical appliances based on their priority so that critical appliances will not be brought down by the high-power consumption usage of non-critical appliances. However, during the period of prolong rainy days, the system may experience great reduction in energy production. In this case, the energy provision will be insufficient for all appliances. Hereby, the proposed scheme shall intelligently cut down power provision for appliances according to its priority for optimum use of available energy. Home appliances can be categorized based on their usage pattern and its importance to the users. For example, the highly demanded appliances will need to operate a longer duration, hence categorizes as higher priority. The appliances that the users cannot live without will have higher priority as well. Owing to that, appliances can be given priority ranking where the appliances with the lowest priority rank will be the first to be cut off from the power system whenever the system starts to run low in its supply. Table II shows an example appliance being categorized with different priority rank as according to the rural community under study.

TABLE II. CRITICAL AND NON-CRITICAL APPLIANCES

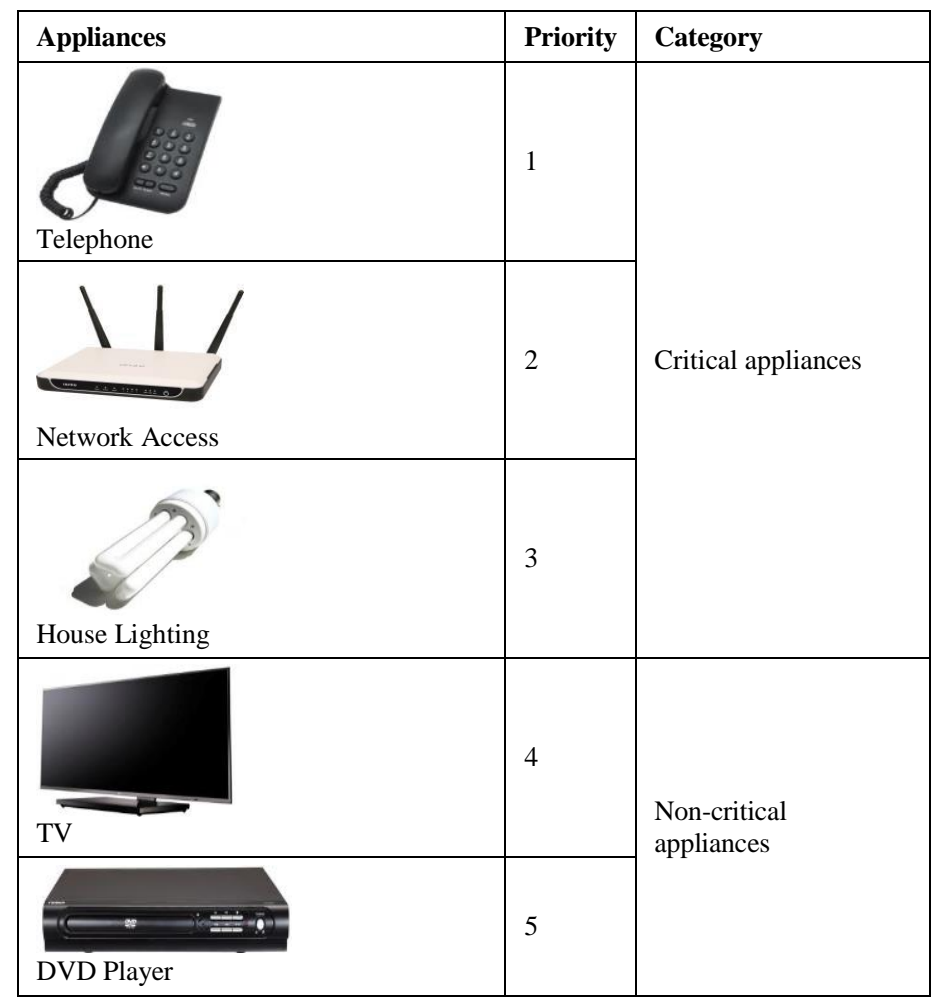


Fig. 3 shows the block diagram of the main components of the proposed priority-based energy distribution scheme for rural home appliances. The scope of the rural appliances has been focused on telephone, network access equipment, house lighting, TV and DVD players. The solar power solely depends on the weather condition where the amount of power generated from the solar panels is depending on the sun hours of that particular area and the rainy season has also been taken into consideration for the simulation of charging and discharging of the associated battery sub-system. In principle, the proposed energy distribution scheme is to assist the existing controller system of the conventional solar power system. The scheme is to provide additional intelligence in decision making for the distribution of power to respective appliances. Users' usage pattern refers to the usage of appliances during peak hours where this information will be used for the priority distribution scheme to regulate the appliances based on their criticality, either to allow them to continue operating during peak hours or cut down their power supply during non-peak hours. The power provision is regulated and energy usage is being optimized through the scheme according to the availability of solar power input of the day, as well as the current charge status of battery subsystem.

\section{B. The Priority - based Distribution Scheme}

The objective of priority-based energy distribution is to improve the usage effectiveness of the generated renewable energy source. That is, stored energy in the battery sub-system is well used for more critical and meaningful purposes. The distribution scheme is dealing two categories of appliances, critical and non-critical. The critical category contains high priority appliances and the non-critical category contains low priority or common appliances. Fig. 6 shows the flowchart of the priority-based energy distribution scheme and how it prioritizes appliances according to high priority, critical and low priority, non-critical categorization. The scheme will also monitor the power input from solar panels as well as the battery power level in order to priorities the appliances accordingly. At the beginning stage of the scheme, the system will check if either the power input is more than 48 Ampere (A) or the battery power level is in the range between 80 to 100 percent (\%), if it does, the system will channel power to all the appliances. This is the comfortable stage of the power system where all appliances regardless of their criticality category, should receive power supply from the system. On the other hand, if either the power input has fall into the range of $41 \mathrm{~A}$ to $48 \mathrm{~A}$ or the battery power level are in between $70 \%$ to $80 \%$, the system will still channel power to all categories of appliances such as telephone, network access hardware, house lighting and TV. It is to note that the system is now at the lower end of the comfortable stage. Next, if either the power input falls between $26 \mathrm{~A}$ to $41 \mathrm{~A}$ or the battery power level goes below 70\%, the system now will only channel power to the critical category of appliances where only the telephone, network access hardware and house lighting are operational. Again, if either the power input gets weaker and falls in between 16A and 26A or the battery power level is in between $55 \%$ to $60 \%$, the system will start to cut off lower priority appliances in the critical category.

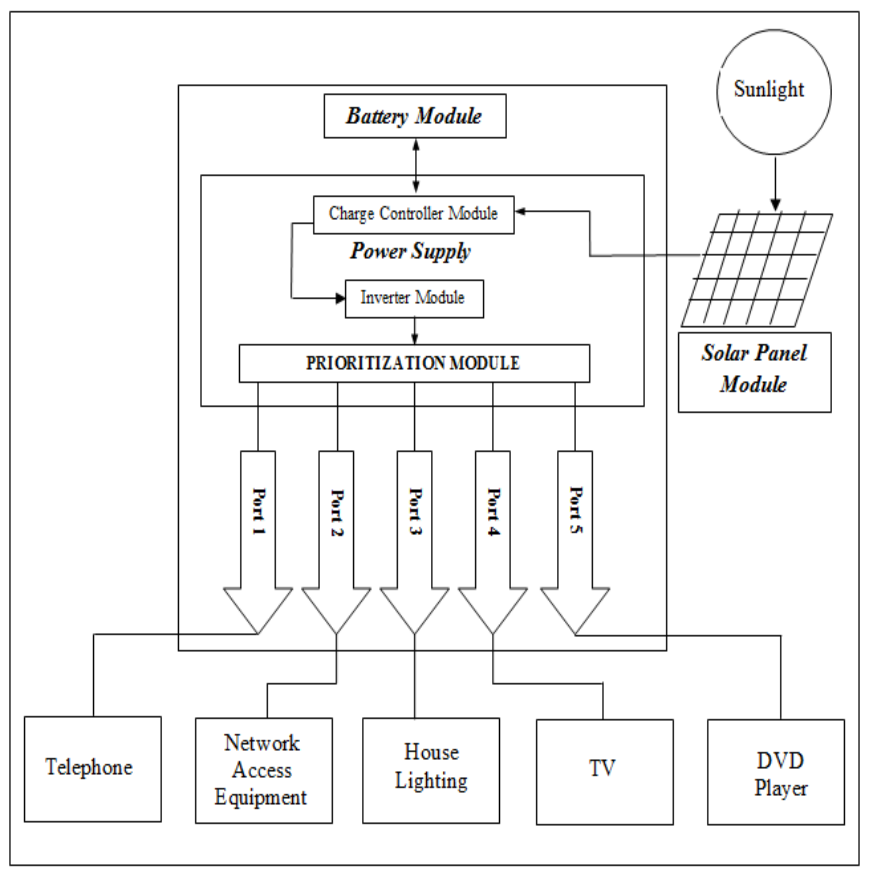

Fig 3. Priority-Based Energy Distribution Scheme for Rural Home.

In this stage, only the highest priority rank appliances, such as the telephone and network access hardware will be operational. Lastly, when either the power input drops below $16 \mathrm{~A}$ or the battery power level is in between $50 \%$ to $55 \%$, the system will only channel power to the highest priority appliance, which is the telephone. If the battery power level hits $50 \%$ or lower, the system will enter battery protection cut off stage where the entire power system will stop supplying power completely. This is where the total system blackout will occur as a counter measure for preventing the battery electrode from being damaged so that it will be able to elongate the battery life span. The solar system will now be waiting for energy input from the solar panels in order to bring the battery level beyond $50 \%$ so that the system will be back to operational again. This usually happens the next day during sunrise. The most critical appliances such as telephone and network access equipment and house lighting are of essential needs compared to the TV and DVD player, thus the proposed scheme will help so that during event of power shortage, the critical appliances will not be brought down by the usage of less essential non-critical appliances.

\section{Simulation Setup, Result And Analysis}

A simulation via MATLAB has been carried out to study the impact of the proposed energy prioritization scheme for Smart Rural Home Appliances in terms of their operating hours. The scheme has been simulated to provision power to the respective hardware based on its priority categories where it will react accordingly based on the different condition of a different time of the day as long as it meets the conditions predefined. The aim is to improve the operational sustainability of the rural appliances during critical hours as well as increase the effective use of energy generated. The evaluation was made based on the results obtained for comparison to a 
standalone conventional solar system on sustaining the most needed services and to prevent total power blackout.

\section{A. Simulation Parameter for Standalone Solar Power and Priority-based Energy Distribution Scheme}

Table III shows a list of the parameters used in the simulation for the comparison between the standalone solar power system and the solar power system with priority-based energy distribution scheme. The performance metrics are based on the total operating hour and their energy efficiency. Both systems have been simulated for a total of 720-unit hours ( 24 hours x 30 days). The same set of weather condition has been used throughout the simulations. That is a combination of sunny, cloudy and rainy days with weather condition indexes ranging from 0 (lowest) to 8 (highest) represented in the simulations. The power consumption rating value for the telephone, network access equipment, home light, TV and DVD player are adapted from online web simulation carry out by Dicrolic (2011) for energy efficient home appliance in rural area. Power consumption of telephone assumed at $1 \mathrm{~A}$, network access equipment is $15 \mathrm{~A}$, home lighting is $10 \mathrm{~A}$, TV usage is $15 \mathrm{~A}$ and DVD player is 7A. The performance metrics are measured via the calculation of the average total operating hours of the all appliances, total battery remaining charge (battery charge storage) and the total energy consumed by both standalone solar power system and the solar power system with the proposed scheme.

TABLE III. LIST OF PARAMETERS FOR SIMULATION

\begin{tabular}{|l|l|}
\hline Parameter & Value \\
\hline $\begin{array}{l}\text { Solar Panel Input (High } \\
\text { Intensity) }\end{array}$ & $42 \mathrm{Amp}$ \\
\hline Weather Condition & $\begin{array}{l}(0-8) \text { no nun light }-8 \\
\text { maximum sun light }\end{array}$ \\
\hline Diesel Power Generator & $60 \mathrm{Amp}$ \\
\hline Days & 30 \\
\hline Hours & 24 \\
\hline Battery Capacity (Minimum) & 500 Amp Hours \\
\hline $\begin{array}{l}\text { Battery Capacity } \\
\text { (Maximum) }\end{array}$ & 1000 Amp Hours \\
\hline Battery Voltage & $12.7 \mathrm{~V}$ \\
\hline $\begin{array}{l}\text { Initial Value of Battery } \\
\text { Capacity }\end{array}$ & $1000 \mathrm{Amp} \mathrm{(100 \% )}$ \\
\hline Telephone & 1 Amp \\
\hline Network Access Equipment & 15 Amp \\
\hline Light & 10 Amp \\
\hline TV & 15 Amp \\
\hline DVD & 7 Amp \\
\hline $\begin{array}{l}\text { Standard User Usage Pattern } \\
\text { Hours }\end{array}$ & 7 p.m. - 12 a.m. per day \\
\hline & $\begin{array}{l}\text { Appliances Total Operating } \\
\text { Hours }\end{array}$ \\
\cline { 2 - 2 } Performance Metric Parameters & $\begin{array}{l}\text { Average Overall Total Battery } \\
\text { Charge Storage }\end{array}$ \\
\hline
\end{tabular}

\section{RESULT COMPARISONS AND DISCUSSIONS}

The output of the randomly generated weather condition and solar panel input in terms of daily and hourly will be shown and discussed in this section followed by the total operating hour for critical and non-critical appliances applied to standalone solar power and solar power system with the proposed energy distribution scheme.

\section{A. Solar Panels Performance under Different Weather Condition}

Fig. 4 shows the weather condition and solar panel input produced randomly on per hour basis for 30 days (30 set data) for various weather occurrences. The weather condition is an important parameter in this simulation as the performance of the critical and non-critical appliances depends heavily on the weather condition. It becomes a decision maker for the power sources that can be conserved by the solar power system and it also determines how much battery charge storage of the energy prioritization scheme can be charged in order to stay active at all-time especially for the critical equipment. Both parameters were monitored in an hourly basis. The solar panels used in this simulation assumed six solar panel modules rated at 100 watts each. With maximum sun intensity, the output of the solar panel array is 600 watts or 42 amps. As seen in Fig. 4 the shape of the graph of the weather conditions and solar panel inputs are of the same pattern as the solar panel input is dependent on the weather condition in order to generate power which is measured in Ampere per hour. This simulation based on various types of weather condition which is unpredictable by its nature. The graph shows that the weather is uncertain for each day, whereby when the weather graph shows a value of 3.4 it is likely to be a sunny day and if in between the range of 0.6 to 3.4 , it is a day with lots of cloud but sunny and finally the range between 0 to 0.5 indicates a rainy day.

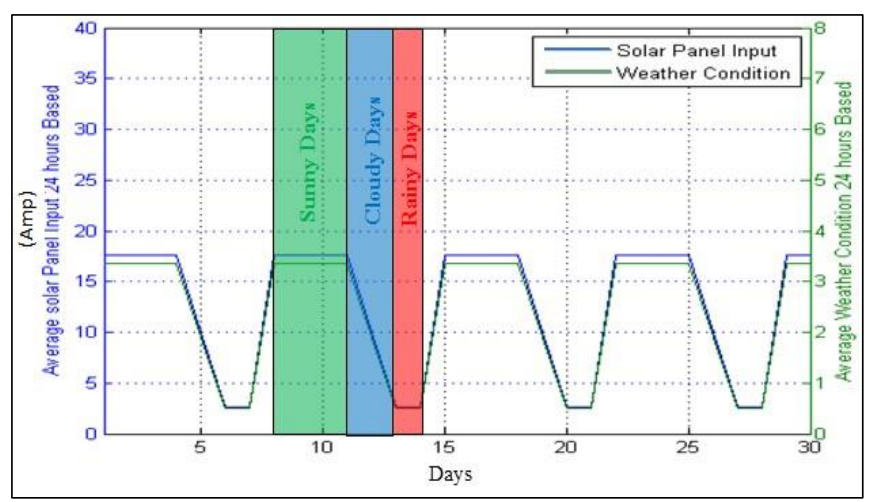

Fig 4. Average Solar Panel Input and Weather Condition.

\section{B. Prioritization of Rural Appliances under Different Weather Condition}

Table IV shows a test scenario that has been used for evaluating the proposed energy distribution scheme on how it performs prioritized-based energy distribution for all appliances under different weather conditions. The appliances involved in this scenario are telephone, network access, house lighting TV and DVD player, and they have been categorized into either critical or non-critical categories. Both simulated 
systems receive only one input source which is the solar power. Simulation time for this scenario is from 7 p.m. to 12 a.m. (5 hours). This is the period where all appliances are usually operational. The performance evaluation is determined by the total operating hours of each of the critical and noncritical appliances from 7 p.m. to 12 a.m. The main focus is on the operating hours of the critical category of appliances as its operating hours have great impact to the rural needs. In order to sustain the critical appliances for longer operating hours, the proposed scheme is crucial so that the usage of non-critical appliances will not bring down the critical appliances by causing total power blackout. Thus, the power provision to the critical and non-critical appliances needs to be regulated so that more optimized energy provision and energy conservation can be achieved in the system. Fig. 5 shows the simulation overall results of operating hours for all appliances powered by the two solar power systems for simulation. It can be seen that appliances regulated by the proposed scheme generally have longer operating time compared to the operating time of the standalone conventional solar power system. The operating hours of the conventional solar system also reflects the operating hours of all appliances powered under the same system. Thus, the proposed scheme plays an important role in intelligently provision power from the battery for more critical appliances or services. The simulations have been running in a way that, day 1 to day 4 , day 8 to day 11 , day 14 to day 17 , day 21 to day 24 and day 27 to day 30 are sunny days and all other days are cloudy and rainy.

\section{Performance Appliances During Sunny Days and Rainy Days}

Fig. 7 compares the operating hours of appliances for the period between 7 p.m. to 12 a.m. on sunny day and rainy day. The operating hours are shown in percentage where $100 \%$ means appliance operate fully for 5 hours from 7 p.m. to 12 a.m. Focusing on the critical appliances, the graph showed that, during sunny days, the operating hour percentage for telephone, network access and light can achieve up to $100 \%$. On the other hand, the conventional solar power system only achieved $20 \%$ of operating time with all appliances switched on. The proposes scheme has been sustaining all the critical appliances for achieving maximum operating hours by cut downs the power provision for non-critical hours which are TV and DVD player. Thus, the percentage of operating hour for the TV and DVD player from 7 p.m. to 12 a.m. during sunny days is only $55 \%$ and $20 \%$ respectively. The operating hours of non- critical appliances have been reduced to top up the hours for the critical appliances under the prioritized scheme. On rainy days the battery sub-system cannot be charged to full during day time. Thus, the remaining battery power is low and not able to provision much power for night hours. In During night period, from 7 p.m. to 12 a.m., the battery power level is in critical stage.

The proposed scheme regulated the power provision by channeling more power for the most critical appliance which is the telephone in this case, to maintain its operating hours to $100 \%$ whereas all other appliances have been sacrifice to give way to the most critical appliance. Even so, the other lower rank critical appliances such as network access equipment and lighting are still getting $20 \%$ of the operating time on a rainy day. On the other hand, it can also be seen that the operating hours of the standalone conventional solar system has operating hours less than 1 hour with all appliances switched on. The solar power system with priority-based energy distribution scheme has demonstrated that it has the ability to sustain operating hours for appliances with critical needs, hence preventing the total power blackout of the system, which usually happened on a non-regulated solar system.

\section{Overall Improvement in Appliances Operating Hours}

Fig. 8 shows average improvement in terms of operating hours achieved for all appliances regulated by the prioritybased energy distribution scheme for the period 7 p.m. to 12 a.m. The average improvement in operating hours for the most critical appliance, the telephone is $462.5 \%$, network access equipment and house lighting achieved average improvement of $293.8 \%$, TV is $125 \%$ and DVD player is a reduction of $20.8 \%$. The DVD player has the lowest priority thus the operating hour is expected to be lesser than others relatively more critical appliances. The operating hours for appliances are different under the regulation of the proposed scheme whereas they are the same under the conventional solar power system. In conclusion, the use of intelligent scheme has created a less stressful situation to ensure the most needed appliances to continue to operate without being affected by overwhelming power usage by other appliances. The remaining power in the battery sub-system can be made good use to meet the rural needs under the situation of limited power supply.

TABLE IV. TEST SCENARIO

\begin{tabular}{|l|l|l|}
\hline System & $\begin{array}{l}\text { Priority-based } \\
\text { Energy Distribution } \\
\text { Scheme }\end{array}$ & $\begin{array}{l}\text { Conventional Solar } \\
\text { Power System }\end{array}$ \\
\hline Weather Condition & Sunny, Rainy \& Cloudy \\
\hline $\begin{array}{l}\text { Appliances (Critical } \\
\text { and Non-Critical) }\end{array}$ & $\begin{array}{l}\text { Telephone Network Access \& House Lighting } \\
\text { TV and DVD Player }\end{array}$ \\
\hline $\begin{array}{l}\text { Input Energy (Only } \\
\text { One) }\end{array}$ & Solar Power (6 Panel) \\
\hline Time & 7 p.m.-12 a.m. (5 hours) \\
\hline
\end{tabular}

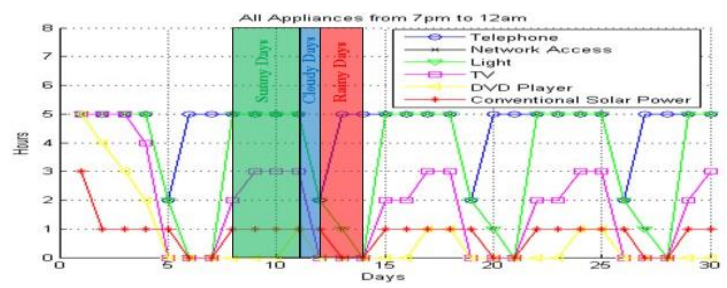

Fig 5. Day to day Performance of Critical and Non-Critical Appliances. 


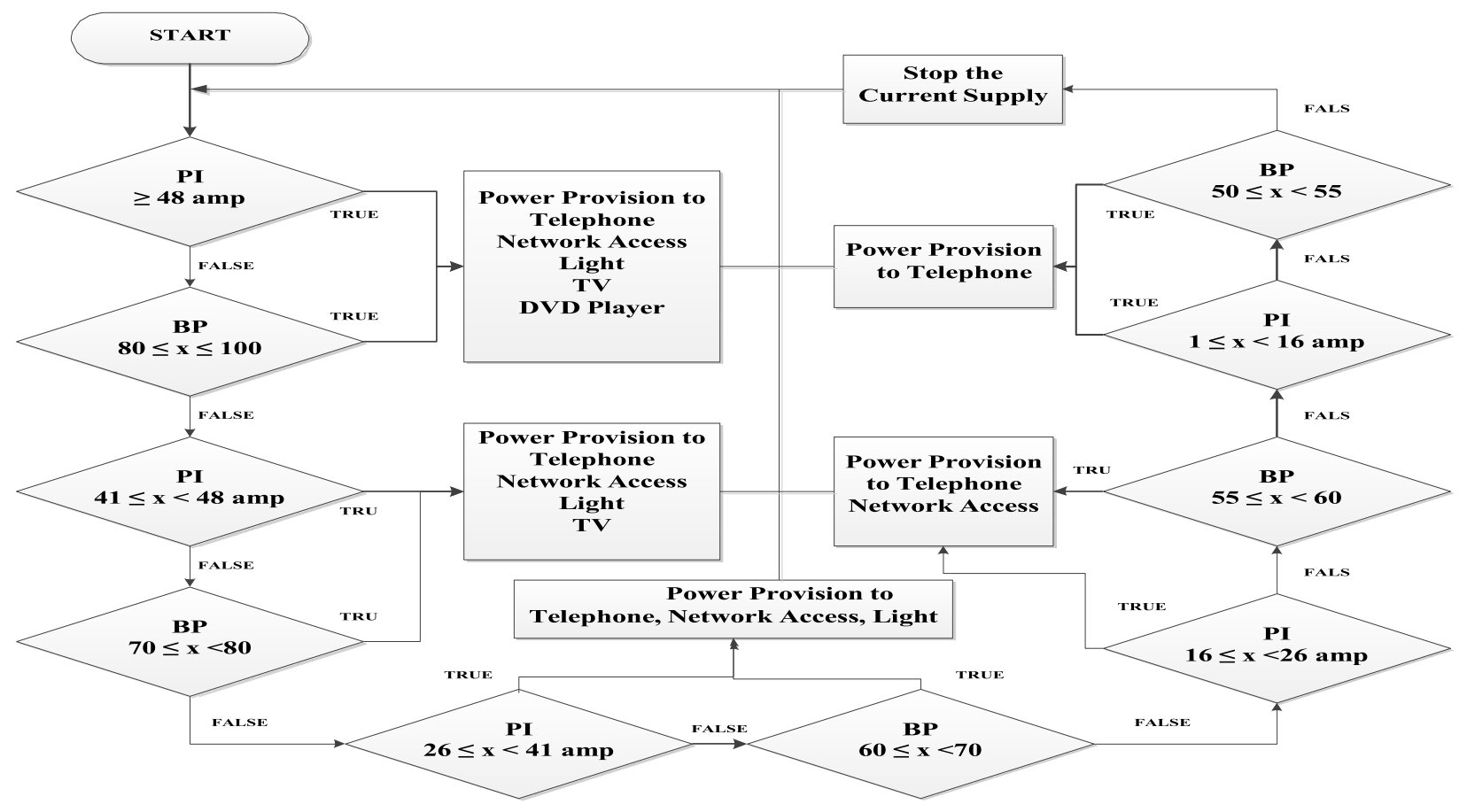

Fig 6. Flowchart of the Priority-Based Energy Distribution Scheme.

Operating hour for all appliances from 7 p.m. to 12 a.m. (5 hours) during different weather condition

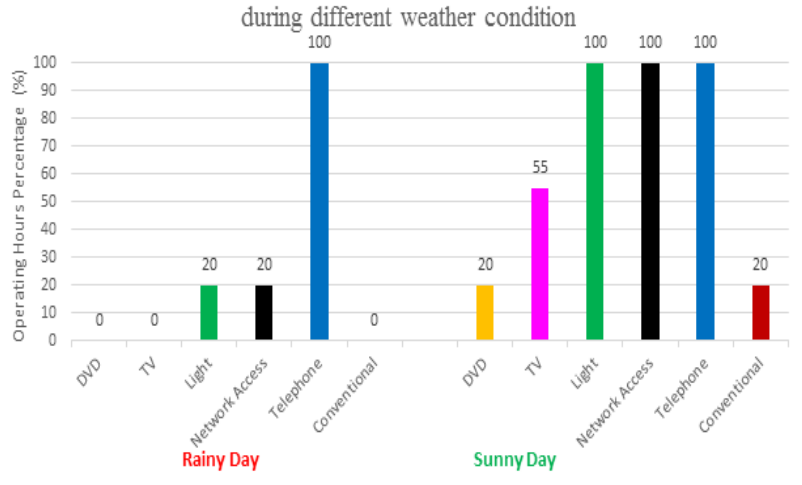

Fig 7. Average Operating Hours of Appliances during Rainy and Dunny Day.

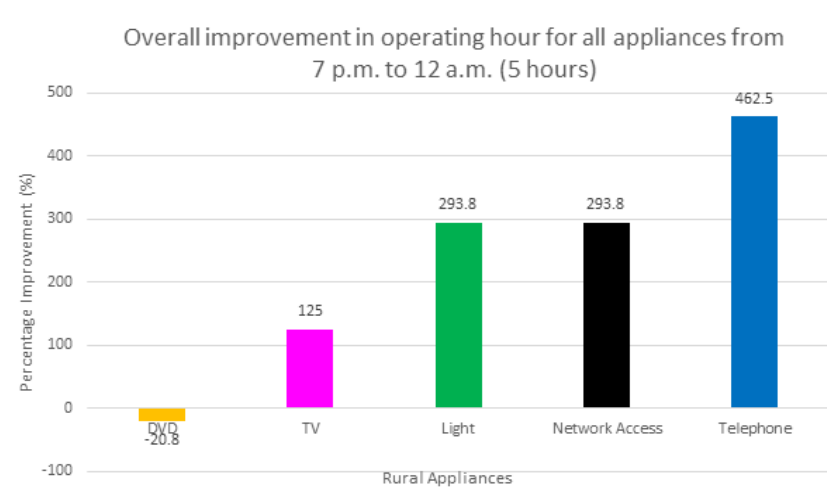

Fig 8. Average Improvement in Operating Hours for Appliances Regulated by the Proposed Scheme.

\section{CONCLUTION}

A new energy distribution scheme has been proposed to ease the unreliable off-grid solar power system. The unreliable issue of the solar power system is usually caused by the mismatch between the amount of power generated and the power usage. It has been very difficult to strike a balance for the two without the help of some intelligent scheme. Hence, we have proposed a priority-based energy distribution scheme that take into consideration of critical needs for its formulation. Through the proposed scheme, the issue of overwhelming power usage can be regulated by the system and at the same time conserve enough power for the more critical higher priority appliances to continue to serve the most important needs in rural living. Through the simulated comparison, the impact of the proposed scheme is meaningful as it has created a possible way to prevent total power blackout that will bring down all services either in a home or an entire village. The basic needs of rural living such as lighting and the ability to communicate with the outside world during any life-threatening occasions must be kept alive at all time. From the simulated results, the proposed energy distribution scheme has the ability to prolong the availability of the critical appliances up to $100 \%$ availability even under the more severe rainy season scenario. With the new scheme in place, the frequency of total system blackout can be greatly reduced and made the system more reliable.

\section{REFERENCES}

[1] Gaur and G. N. Tiwari, "Exergoeconomic and enviroeconomic analysis of photovoltaic modules of different solar cells," Journal of Solar Energy, DOI: 10.1155/2014/719424, vol. 2014, 8 pages, 2014

[2] P. K. Sahoo, "Exergoeconomic analysis and optimization of a cogeneration system using evolutionary programming," Applied Thermal Engineering, DOI: 10.1016/j.applthermaleng.2007.10.011, vol. 28, no. 13, pp. 1580-1588, 2008. 
[3] C. Wei-Nee, "Renewable Energy Status in Malaysia", Sustainability Energy Development Authority Malaysia, 2012.

[4] Subiyanto, A. Mohammed and M.A. Hannan, "Intelligent photovoltaic maximum power point tracking controller for energy enhancement in renewable energy system," Journal of Renewable Energy, DOI: 10.1155/2013/901962, vol.2013, Article ID 901962, 9 pages, 2014

[5] T. J. Hammons, J. C. Boyer, S. R. Conners et al., "Renewable energy alternatives for developed countries," IEEE Transactions on Energy Conversion, DOI: 10.1109/60.900511, vol. 15, no. 4, pp. 481493, 2000.

[6] O. Gil-Arias and E. I. Ortiz-Rivera, "A general purpose tool for simulating the behavior of PV solar cells, modules and arrays," in Proceedings of the 11th IEEE Workshop on Control and Modeling for Power Electronics (COMPEL '08), DOI: 10.1109/COMPEL.2008.4634686, pp. 1-5, August 2008.

[7] B. Kamanga, J. S. P. Mlatho, C. Mikeka, and C. Kamunda, "Optimum Tilt Angle for Photovoltaic Solar Panels in Zomba District, Malawi," Journal of Solar Energy, DOI: 10.1155/2014/132950 vol. 2014, Article ID 132950, 9 pages, 2014

[8] E. Calabrò, "An algorithm to determine the optimum tilt angle of a solar panel from global horizontal solar radiation," Journal of Renewable Energy, DOI: 10.1155/2013/307547 vol. 2013, Article ID 307547, 12 pages, 2013.

[9] U.H. Ibrahim, D.A. Aremu and J.L. Unwaha, "Design Of Stand-Alone Solar Photovoltaic System For Residential Buildings," in International Journal of Scientific \& Technology Research, vol.2, no.2, pp 187-194, 2013.

[10] W.A.Ahmad-Kazwini, "Aplication of Solar Energy in Malaysia," Faculty of Engineering University of Malaya Kuala Lumpur, 2011

[11] U. Saher, K. Mineo, T. Yasuo and L.O. Azman, "Priority based maximum consuming power control in smart homes," in IEEE. Innovative Smart Grid Technologies Conference, DOI: 10.1109/ISGT.2014.6816400, pp 1-5, 2014.

[12] P. Miroslav \& H. Ales, "Priority-Based smart household power control model," in IEEE Cons. Electrical Power and Energy Conference, DOI: 10.1109/EPEC.2012.6474976, pp 337- 343, 2012

[13] P. Manisa, K. Muzlu \& R. Saifur, "An algorithm for intelligent home energy management and demand response analysis" in IEEE Trans. Smart Grid, DOI: 10.1109/TSG.2012.2201182, vol. 3, no. 4, pp. $2166-2173,2012$
[14] L. Xin, I. Liviu, K. Rui and M. Martin, "Real-time household load priority scheduling algorithm based on prediction of renewable source availability," in IEEE Trans. Consumer Electronics, DOI: 10.1109/TCE.2012.6227429, vol. 58, no.2, pp. 318-326, 2012.

[15] K. Takekazu, Y.Kenji and M.Takashi, "Energy on Demand Efficient and Versatile Energy Control System for Home Energy Management," in IEEE Conf. Smart Grid Communications, DOI: 10.1109/SmartGridComm.2011.6102354, pp. 392 - 397, 2011.

[16] K. Gill, S.-H. Yang, F. Yao, and X. Lu, "A zigbee- based home automation system," IEEE Trans. Consumer Electron., DOI: 10.1109/TCE.2009.5174403, vol. 55, no. 2, pp. 422-430, 2009

[17] D.-M. Han and J.-H. Lim, "Smart home energy management system using IEEE 802.15.4 and zigbee," in IEEE Trans. Consumer Electron., DOI: 10.1109/TCE.2010.5606276, vol. 56, no. 3, pp. 1403-1410, 2010.

[18] D.M. Han and J.-H. Lim, "Design and implementation of smart home energy management systems based on zigbee," IEEE Trans. on Consumer Electron., DOI: 10.1109/TCE.2010.5606278, vol. 56, no. 3, pp. 1417-1425, 2010.

[19] P. Zhao, S. Suryanarayanan, \& M. G. Simoes, "An Energy Management System for Building Structures Using a Multi-Agent Decision-Making Control Methodology," in IEEE Trans. Industry Applications Society Annual Meeting (IAS), DOI: 10.1109/TIA.2012.2229682, vol. 49. No. 1, pp. 322-330, 2010.

[20] N. Nhat-Hai, T. Quoc-Tuan, J. M. Leger, \& V. Tan- Phu, "A real-time control using wireless sensor network for intelligent energy management system in buildings," in IEEE Workshop. Environmental Energy and Structural Monitoring Systems (EESMS), DOI: 10.1109/EESMS.2010.5634176, pp. 87-92, 2010.

[21] H. Mineno, Y. Kato, K. Obata, H. Kuriyama, K. Abe, N. Ishikawa, \& T. Mizuno, "Adaptive Home/Building Energy Management System Using Heterogeneous Sensor/Actuator Networks," in IEEE Conf. Consumer Communications and Networking Conference (CCNC), DOI: 10.1109/CCNC.2010.5421762, pp. 1-5, 2010.

[22] A. Yuvaraj, B. Bharathan. G. Rajesh, L. Jacob, W. Michael, \& W. Thomas, "Occupancy driven energy management for smart building automation," ACM Workshop. On Embedded Sensing Systems for Energy-Efficiency in Building, DOI: 10.1145/1878431.1878433, 2010.

[23] C. Wei \& Y. Li, "Design of energy consumption monitoring and energy saving management system of intelligent building based on the Internet of things," in IEEE Conf. International Conference on Electronics, Communications and Control (ICECC), DOI: 10.1109/ICECC.2011.6066758, pp. 3650-3652, 2011. 